\title{
POLÍTICAS PÚBLICAS EDUCACIONAIS E AS EXPRESSÕES DA QUESTÃO SOCIAL PRESENTES NO ENSINO SUPERIOR PÚBLICO
}

\author{
PUBLIC EDUCATION POLICY AND SOCIAL ISSUE EXPRESSIONS GIFTS IN \\ HIGHER EDUCATION PUBLIC
}

\author{
Mariana Rosa Alves Ladeira ${ }^{1}$ e Rosane Aparecida de Sousa Martins ${ }^{2}$
}

\begin{abstract}
RESUMO
A educação superior no Brasil é tema de um amplo debate, e em diversas áreas dos saberes; para tanto, deve-se pensar também acerca de sua função social; da inserção e permanência das classes menos favorecidas no Ensino Superior Público; no tripé ensino, pesquisa e extensão; e nas políticas públicas educacionais. O presente artigo visa a contribuir para a discussão acerca das influências do neoliberalismo e da globalização na educação, tendo em vista os determinantes históricos que trazem consigo fortes resquícios de um tempo em que apenas a elite, minoria da população, tinha acesso ao ensino superior. Discute-se a questão social e suas expressões presentes na universidade, além de resultados de um estudo realizado na Universidade Federal do Triângulo Mineiro, por meio de uma pesquisa de campo, de abordagem quanti-qualitativa; em que os discentes beneficiados pelo Programa de Assistência Estudantil, versam sobre a contribuição dos auxílios para a permanência no ensino superior público. Assim, identifica-se que faz-se necessário maiores investimentos nas Políticas Educacionais, garantindo o acesso igualitário à educação, além de meios para prover a permanência desses estudantes no ensino superior público.
\end{abstract}

Palavras-chave: Educação Superior. Assistência Estudantil. Questão Social.

\begin{abstract}
Higher education in Brazil is the subject of considerable debate, and in several areas of knowledge; to do so, one must also think about its social function; the insertion and retention of the lower classes in public higher education; tripod in teaching, research and extension; and educational public policies. This article aims to contribute to the discussion about the influences of neo-liberalism and globalization in education, in view of the historical factors that bring with them strong remnants of a time when only the elite, the population of the minority, had access to higher education. It discusses the social issue and its expressions present at the university, as well as results of a study conducted at the Federal University of Triangulo Mineiro, through field research of quantitative and qualitative approach; where the students benefited from the Student Assistance Program, deal with the contribution of aid to stay in public higher education. Thus it identifies that it is necessary greater investment in educational policies, ensuring equal access to education, and means to provide the permanence of these students in public higher education.
\end{abstract}

Keywords: Higher educatio. Student assistance. Social Issues.

1 UNESP - Universidade Estadual Paulista "Júlio de Mesquita Filho" - Franca/SP. Email: mari.ladeira@hotmail.com

${ }^{2}$ Universidade Federal do Triângulo Mineiro - UFTM. Email: drarosane.martins@gmail.com 


\section{INTRODUÇÃO}

A história da educação no Brasil é marcada por lutas e disputas de projetos societários de diferentes grupos sociais, tendo forte ligação com as transformações na cultura, no mundo do trabalho e nas relações sociais; constituindo assim, um campo de forte hegemonia política, social, econômica e cultural na sociedade. Foi a partir da Constituição Federal de 1988 que a educação foi instituída como direito de todos e dever do Estado e da família. A Lei de Diretrizes e Bases da Educação - LDB, Lei 9.394, de 20 de dezembro de 1996, veio complementar e reafirmar a Constituição, baseando-se no direito universal à educação e trazendo propostas de ações, vislumbrando um sistema de ensino mais igualitário e acessível a todos, especialmente no ensino superior.

A perspectiva da inclusão social e da democratização do ensino para todos os cidadãos, presente nesse contexto, é corroborada pelo artigo 205 da Constituição Federal de 1988, que versa sobre a educação como direito de todos, e dever do Estado e da família; e o artigo 206 que prevê a igualdade de condições de acesso e permanência na escola. Assim sendo, os programas de assistência vêm legitimar a proposta de diminuir a evasão dos alunos das universidades, bem como fomentar a ideia de que o acesso ao ensino superior deve ser indissociável da permanência dos discentes nas instituições.

O Decreto n. ${ }^{\circ}$ 7.234, de 19 de julho de 2010, que dispõe sobre o Programa Nacional de Assistência Estudantil - PNAES, executado no âmbito do Ministério da Educação, apoia a permanência de estudantes de baixa renda, matriculados em cursos presenciais de graduação das Instituições Federais de Ensino Superior - IFES, viabilizando igualdade de oportunidade entre todos os discentes e contribuindo para que o estudante tenha um desempenho acadêmico satisfatório, articulado com atividades de ensino, pesquisa e extensão. Para isso, são desenvolvidas ações, pela própria instituição de ensino, que visam acompanhar e avaliar o desenvolvimento do programa, que oferece assistência à alimentação, transporte, moradia, saúde, cultura, inclusão digital, esporte, creche, apoio pedagógico, dentre outros benefícios.

Para tanto, o presente artigo, resultado de pesquisa registrada no Comitê de Ética em Pesquisa/UFTM Protocolo n. ${ }^{\circ}$ 2641, visa a contribuir para a discussão acerca das expressões da questão social presentes na universidade púbica, tendo em vista os determinantes históricos que trazem consigo fortes resquícios de um tempo em que apenas a elite, minoria da população, tinha acesso ao ensino superior. Além de trazer alguns dos resultados de um estudo realizado na Universidade Federal do Triângulo Mineiro, em que os discentes, 
beneficiados pelo Programa de Assistência Estudantil, versam sobre a contribuição dos auxílios para a permanência no ensino superior público.

Vê-se então que é relevante que se entenda primeiramente um pouco da história do ensino superior brasileiro, para discutir sobre as interferências do neoliberalismo na educação; e, adiante, desvelar as facetas das expressões da questão social no ensino superior público.

\section{O ENSINO SUPERIOR BRASILEIRO: UM BREVE RESGATE HISTÓRICO}

A universidade pública deve ser polo de formação acadêmica, cultural, política e intelectual, e não apenas um ambiente que forme profissionais para atuar no mercado de trabalho. Ela deve cumprir sua função social de universidade, formadora de cidadãos críticos e dispostos a participar dos assuntos da comunidade, promovendo transformações sociais coletivas. Sua função social se evidencia por meio de projetos de pesquisa, extensão, cursos abertos à comunidade externa, dentre outros meios de interação e troca de saberes entre universidade e comunidade.

Em seus estudos, Saviani (2008, p. 2) relembra a origem da palavra 'escola', que em grego significa lazer, ócio, tempo livre; ou seja, nos primórdios, a educação era reservada à minoria, à elite, enquanto os demais trabalhadores garantiam a produção de sua existência, uma vez que:

[...] para continuar existindo o homem necessita produzir sua própria existência. E a forma de sua existência é determinada pelo modo como ele a produz ou, já que o homem só existe em sociedade, a forma da sociedade é determinada pelo modo como é produzida a existência humana em seu conjunto (SAVIANI, 2008, p. 1).

E ainda hoje há resquícios desse tempo, visto que muitos trabalhadores não dispõem de tempo livre para se dedicar aos estudos, pois os salários são baixos, e as horas extras culminam num processo de maior exploração como mecanismo de subsistência, mas que faz diferença na sociedade capitalista em que se vive. E para participar ativamente dessa vida em sociedade é preciso ser trabalhador produtivo, o que demanda submissão aos moldes do trabalho na contemporaneidade.

Tal situação exige refletir também sobre o ingresso na cultura letrada, já que o mercado de trabalho demanda uma qualificação profissional e um processo educativo sistemático. Quem mais se qualifica tem maiores chances no mercado produtivo. No entanto, 
nem todos têm tempo para se dedicarem aos estudos, o que segrega ainda mais a população, ampliando a distância entre os que têm acesso a uma universidade e os que têm de trabalhar longas jornadas para prover seu sustento.

Ao longo da história, a universidade tem se apresentado como uma instituição em movimento, permeada de ideologias e valores do mundo do trabalho, mas também com forte poder de mudança, de renovação e de construção de pensamentos críticos. Nesse contexto, busca-se resgatar alguns marcos históricos, retratando uma história de lutas, conquistas e entraves que influenciam direta e indiretamente a questão educacional da sociedade contemporânea.

Identifica-se na história das instituições universitárias que seu objetivo inicial seria atender à classe burguesa e aos seus interesses econômicos, desde sua base na Europa, na Baixa Idade Média, séculos XI a XIV. No Brasil, o surgimento das universidades foi retardado pela coroa portuguesa, uma vez que era de seu interesse monopolizar as elites com os estudos provindos de Coimbra. Apenas em 1808, com a chegada da família real, foram permitidas as primeiras instituições de ensino superior, de cunho profissionalizante nas áreas do Direito, Medicina e Engenharia.

No Brasil, a Universidade Federal do Amazonas (UFAM) é considerada a primeira universidade pública, originada a partir da Escola Universitária Livre de Manáos, criada em janeiro de 1909. A segunda mais antiga instituição de ensino superior com o status de universidade é a Federal do Paraná, surgida em 1912 com o nome Universidade do Paraná. O modelo universitário implantado no país, na década de 1930, tinha como escopo principal formar uma elite intelectual para servir às demandas da classe dominante e da indústria nascente (BENINCÁ, 2011, p. 33).

Pode-se dizer que, no Brasil, esse debate mais abrangente acerca da política de educação data da instalação da República, e foi a partir da década de 1920 que a questão educacional ganhou um espaço social mais amplo. Foi nesse período que essa questão começou a ser percebida como um problema de âmbito nacional, e não apenas como tema de reflexões isoladas.

Como citado anteriormente, até 1930 as universidades eram extremamente elitistas, com forte influência da Igreja Católica, que detinha o monopólio da educação, e se defrontavam com os manifestos dos chamados "inovadores liberais", que lutavam em defesa de uma educação fundamental e universalista. Em 1930, foi criado o Ministério da Educação 
e Saúde; e o primeiro ministro Francisco Campos criou o Conselho Nacional de Educação, estabelecendo também o Estatuto das Universidades Brasileiras.

Os "inovadores" da educação, já mencionados, reuniram-se através da Associação Brasileira de Educação - ABE, culminando mais tarde, em 1932, no "Manifesto dos Pioneiros da Educação", evento que teve grande repercussão, e motivou uma campanha que resultou no abarcamento de um artigo específico na Constituição Brasileira de 16 de julho de 1934. O artigo 150, que afirmava ser competência da União "fixar o plano nacional de educação, compreensivo de ensino de todos os graus e ramos, comuns e especializados; e coordenar e fiscalizar a sua execução, em todo o território do País". Além de atribuir ao Conselho Nacional de Educação, a elaboração do plano aprovado pelo Legislativo, que buscou medidas e soluções para as questões educacionais e a destinação de verbas e fundos.

O chamado período populista, compreendido entre 1930 e 1964, é entendido como uma passagem do processo econômico, em que se substitui a principal atividade agroexportadora para o predomínio da produção industrial; sendo então iniciado um processo de renovação e expansão do sistema público, marcado por algumas conquistas, dentre elas a Constituição de 1934, que estabeleceu a elaboração de um Plano Nacional da Educação PNE, já proposto desde os manifestos dos pioneiros.

A proposta do plano foi debatida pelo Congresso Nacional; no entanto, em 1937, Getúlio Vargas dá um golpe político, e o projeto de transformar o PNE em lei se torna ainda mais distante. Com a elaboração da Constituição de 1946, a União foi encarregada de elaborar a Lei de Diretrizes e Bases da Educação Nacional, mas o plano só viria com a LDB em 1961. Mas a própria LDB de 1961, Lei $\mathrm{n}^{\circ} 4.024$, ainda carregava um caráter elitista, visto que a educação ainda era privilégio da classe dominante.

Foi no governo de Juscelino Kubitschek (1956 - 1961) que começou a surgir efetivamente a primeira ideia de um plano de educação; e foi em seu Plano de Metas que houve a idealização de um plano que contemplasse as particularidades da educação. Antes disso foram feitas propostas e sugestões, mas nada concreto. Como ressalta Azanha (1993), "foi preciso um longo período de maturação para que se formulasse explicitamente a necessidade nacional de uma política de educação e de um plano para implementá-la”.

No período compreendido entre 1968 a 1988, houve uma maior preocupação em "reorganizar" a universidade com vistas à implementação de uma estrutura mais tecnicista, de estrutura departamental, mas que censurava os pensamentos críticos, e se submetiam aos moldes capitalistas. Por isso, na década de 1980, em contexto de redemocratização, abriu-se o 
debate acerca do controle exercido pelo governo, culminando na Constituição Federal de 1988, cujo artigo 207 prevê que "as universidades gozam de autonomia didático-científica, administrativa e de gestão financeira e patrimonial, e obedecerão ao princípio de indissociabilidade entre ensino, pesquisa e extensão".

A partir da década de 1990 a "economia brasileira teve forte subordinação ao capital financeiro transnacional, o que fortaleceu a lógica neoliberal em praticamente todos os âmbitos da sociedade" (BENINCÁ, 2011, p. 37). Assim, a mercantilização da educação se fortalecia, preparando profissionais capacitados para o mercado de trabalho e para atender aos interesses neoliberais, mas sem criticidade para propor melhorias nas condições de trabalho e sanar as demandas da classe trabalhadora. Assim, "o conhecimento, a ciência e as próprias instituições de ensino acabam por se tornar peças na engrenagem do sistema" (BENINCÁ, 2011, p. 38).

E no processo de globalização, presente na atualidade, identificam-se as mazelas da sociedade, provenientes das expressões da questão social; que afetam diretamente a política educacional brasileira.

No reino do capital, a educação é, ela mesma, uma mercadoria. Daí a crise do sistema público de ensino, pressionado pelas demandas do capital e pelo esmagamento dos cortes de recursos dos orçamentos públicos. Talvez nada exemplifique melhor o universo instaurado pelo neoliberalismo, em que "tudo se vende, tudo se compra", "tudo tem preço", do que a mercantilização da educação. Uma sociedade que impede a emancipação só pode transformar os espaços educacionais em shopping centers, funcionais à sua lógica do consumo e do lucro (MESZÁROS, 2008, P. 16).

O enfraquecimento da educação pública e a expansão do sistema privado, reforça a ideologia dominante do mercado, do consumo, e de uma educação mercadológica, como mencionado na citação de Mészaros.

Em meio a esse breve recorte da educação superior no Brasil, e as particularidades de sua história, percebe-se que há uma evolução no que concerne às iniciativas para expansão, acesso e permanência na educação superior, mesmo que o mercado do ensino profissionalizante e técnico ainda esteja fortemente visado por capacitar em menos tempo para o mercado de trabalho.

Para tanto, deve-se considerar que a reestruturação do Estado Brasileiro na década de 1990, caracterizada pela chegada da esperada democracia, introduziu mudanças nas relações entre Estado, sociedade e mercado. "A educação embutiu elementos marcados por valores de 
mercado" (SILVA; MARQUES, 2008, p. 53), passando, portanto, a legitimar a lógica capitalista, em que se prima mais pelo financeiro, pelo econômico e pelos interesses burgueses.

Portanto, a educação tem uma estreita relação com as transformações econômicas, culturais, políticas e sociais, trazendo consigo fortes interferências do mundo do trabalho, da globalização, da chegada de novas tecnologias, e do modelo neoliberal. Foram muitos os avanços e conquistas com as mudanças societárias, mas também alguns entraves que devem ser superados; assim como alguns avanços necessários, como a necessidade de efetivação das legislações e metas definidas para melhorias na política educacional. Assim, adiante, será abordado sobre as expressões da questão social na universidade, com vistas a apresentar os resultados de pesquisa realizada.

\section{AS EXPRESSÕES DA QUESTÃO SOCIAL PRESENTES NA SOCIEDADE CAPITALISTA: DESAFIOS INTERPOSTOS ÀS UNIVERSIDADES}

O debate acerca da Política de Assistência Estudantil vai além do mero entendimento da educação superior e sua trajetória, mas supõe enxergar as demandas e necessidades impostas pelo cenário atual. Cenário de consumismo e alienação, que prega ideologias neoliberais com vistas a buscar uma hegemonia social, lugar em que não haja reflexão, posicionamentos e participação ativa na sociedade e nas decisões públicas. A própria educação é dita como um vexame, (DEMO, 1997, p. 50) uma aprendizagem que pode estar desatualizada de seu tempo, e que exige posicionamento dos educadores, educandos, família e comunidade, para que ocorram mudanças efetivas.

Uma das críticas mais frequentes que se ouvem, hoje, a respeito da educação, [...] é de que ela estaria desatualizada, em descompasso com as exigências e necessidades atuais da sociedade. E certamente existem dados suficientes para comprovar que essas críticas são verdadeiras (TONET, 2012, p. 13).

Percebe-se que o sistema capitalista, de ideologia neoliberal, tem contribuído para a criação de um ambiente em que o Estado cerceia as liberdades individuais dos cidadãos, difundindo um conceito de igualdade perante as leis, mas não promovendo um acesso igualitário às oportunidades. Oportunidades que começam pelos direitos fundamentais, como essa educação de qualidade. Começa também pelo mundo do trabalho, em que a precarização 
é muito forte, sem falar na terceirização e subcontratação. Frutos de um país que passou e passa por intensas transformações, em que o cenário é palco das expressões da "questão social"; a compreensão desse assunto é primordial e será abordado de agora em diante, para situar suas facetas também no contexto da universidade pública.

O mundo capitalista atravessa, nestas últimas décadas, um período de profundas modificações nos seus padrões de produção, de acumulação e de concorrência, implicando "novos" desafios tanto para os Estados e seus governos, quanto para os setores que representam o capital e para as classes trabalhadoras (no que se refere à sua inserção na estrutura produtiva, organização coletiva, representação política etc.) (PASTORINI, 2010, p. 37).

Percebe-se então, que essas mudanças interferem no modo de vida das pessoas, uma vez que a pobreza acirra, o pauperismo, a exclusão social, a massa de trabalhadores desempregados, ou inseridos no mercado informal também. Ou seja, mudanças que segregam a população, reforçando a divisão em classes sociais, que, por vezes, são mascaradas por um discurso de igualdade do governo, que não passa de um 'discurso' apenas.

[...] o "modelo" é um Estado que reduz suas intervenções no campo social e que apela à solidariedade social, optando por programas focalistas e seletivos caracterizados por ações tímidas, errádicas e incapazes de alterar a imensa fratura entre necessidades $\mathrm{e}$ possibilidades efetivas de acesso a bens, serviços e recursos sociais. [...] Assim, as propostas neoliberais, em relação ao papel do Estado quanto à questão social, são propostas reducionistas que esvaziam e descaracterizam os mecanismos institucionalizados de proteção social. São propostas fundadas numa visão de política social apenas para complementar o que não se conseguiu via mercado, família ou comunidade (YASBEK, 2001, p. 37).

Dessa maneira, busca-se a legitimação de uma ordem coercitiva, mas que mascara toda a realidade, o pauperismo, a fome da grande parcela dos assistidos, que por vezes têm algumas necessidades supridas, mas não têm oportunidades para adentrar o mercado de trabalho, prover sua subsistência e caminhar rumo à sua emancipação.

Tudo isso é resquício de séculos de vigência do capitalismo, que acumula riquezas, assim como uma massa de trabalhadores, em situação de pobreza acentuada e generalizada. Não obstante a legitimação, busca-se a conformação com tal situação, e cada vez mais a "questão social" e suas expressões são naturalizadas. É como versa Yasbek (2001, p. 37): 
"Décadas de clientelismo consolidaram uma cultura tuteladora que não tem favorecido o protagonismo nem a emancipação dessas classes em nossa sociedade”.

Para definir uma concepção do que seria a chamada "questão social", Iamamoto (2001) traz em seus excertos algumas ideias que contribuem para o debate posterior, assim como para o entendimento das problematizações acerca da temática:

A questão social diz respeito ao conjunto das expressões das desigualdades engendradas na sociedade capitalista madura, impensáveis sem a intermediação do Estado. Tem sua gênese no caráter coletivo da produção, contraposto à apropriação privada da própria atividade humana - o trabalho -das condições necessárias à sua realização, assim como de seus frutos (IAMAMOTO, 2001, p. 16).

E para tratar dessa chamada "questão social", entende-se que falar sobre suas expressões é muito mais do que uma trajetória unidimensional. Trata-se de uma unidade de contradições e ambigüidades, de ir além, pensar que a "questão social" está intimamente ligada ao desenvolvimento do capitalismo e à consequente desigualdade social vivida pela classe trabalhadora.

É válido frisar que, mesmo dessa forma, ainda se entende que foi com a ampliação da ideologia do neoliberalismo em meados dos anos 1980, que fazemos referência como um marco do agravamento das expressões da questão social, e é a partir desse período que o raciocínio se segue. Salientam-se as mudanças no modo de produção, de períodos anteriores, fordismo, taylorismo e toyotismo ${ }^{1}$, como elementos que vão afetar diretamente as relações de produção e reprodução social. É a chamada reestruturação produtiva, de um trabalhador polivalente, que executa trabalhos mecanicistas, cumpre longas jornadas e muitas horas extras por ínfimos salários. Mas o que está no centro dessa discussão é o que isso tem acarretado na vida social da classe trabalhadora e quais as repercussões no mundo contemporâneo. Pastorini (2010, p. 114), afirma que a "questão social" possui três pilares:

[...] em primeiro lugar, podemos afirmar que a "questão social" propriamente dita remete à relação capital/trabalho (exploração), seja vinculada diretamente com o trabalho assalariado ou com o "não trabalho"; em segundo, que o atendimento da "questão social" vinculase diretamente àqueles problemas e grupos sociais que podem colocar em xeque a ordem socialmente estabelecida [...]; e, finalmente, que ela é expressão das manifestações das desigualdades e antagonismos ancorados nas contradições próprias da sociedade capitalista (PASTORINI, 2010, p. 114). 
E nessas contradições próprias da sociedade capitalista, encontra-se um Estado que muitas vezes é manipulado e refém do mercado, encolhendo sua "ação reguladora". É redefinido um novo papel para ele, o chamado "Estado Mínimo", que é mínimo para o social, mas máximo para o capital, já dizia José de Paulo Netto em seus estudos. Um Estado que limita suas intervenções em defesa do capital, do processo econômico do país, tudo pelo seu "desenvolvimento". Além de criar políticas públicas sociais que não superam sua abordagem fragmentada e reparatória, ao contrário, são concebidas na ideologia do favor, da ajuda, um governo paternalista, com ações "filantrópicas".

Tal fato aprofunda a alienação durante esse processo, fazendo com que as pessoas não tenham consciência do mundo em que vivem, da exploração, dos altos impostos, dos juros infindáveis. É uma modernização excludente, que segrega, que naturaliza as desigualdades sociais. E essa falta de questionamento e participação nas decisões públicas e políticas "leva a uma perda da processualidade nas análises dos fenômenos [...] a exclusão, a pobreza e até o próprio capitalismo se apresentariam como fatos dados." É evidente o conservadorismo impregnado na sociedade, ideologias hegemônicas, em que "cria-se e alimenta-se a ilusão de um futuro melhor [...] quando na verdade todos esses fenômenos são produto da opressão econômica, política e cultural exercida pelas classes dominantes na ordem capitalista" (PASTORINI, 2010, p. 91).

[...] as principais manifestações da "questão social" - a pauperização, a exclusão, as desigualdades sociais - são decorrências das contradições inerentes ao sistema capitalista, cujos traços particulares vão depender das características históricas da formação econômica e política de cada país e/ou região. Diferentes estágios capitalistas produzem distintas expressões da "questão social" (PASTORINI, 2010, p. 101).

Nesse sentido, essas distintas expressões da questão social são vestidas de novas roupagens, de acordo com o tempo e sistema em que se vive; para tanto, corrobora-se com a ideia que de não existe uma "nova questão social" como alguns autores acreditam; ela apenas metamorfoseia-se. Assim, presencia-se um novo tempo, mas uma renovação da "velha questão social", de acordo com as condições contemporâneas e sócio-históricas. Seria um contexto de globalização que acirra cada vez mais a fome, a miséria, o desemprego, a pauperização; ou seja, "velhas expressões da questão social", mas ao mesmo tempo muito atuais, que assumem novas facetas sob a égide do capitalismo e a produção acentuada da desigualdade (IAMAMOTO, 2001, p. 18-21). 
Assim, há um desmonte das políticas públicas e consequentemente a fragilização, fragmentação e retrocesso dos direitos conquistados ao longo do tempo. Tal fato é reforçado pela ideologia neoliberal que tende a reduzir as dimensões civis e políticas do Estado, transferindo responsabilidades ao mercado e a outros segmentos da sociedade civil, fazendo com que haja uma regressão da cidadania e menos participação da população. É a lógica das políticas sociais focalizadas, supracitadas. José Paulo Netto (2001) menciona a emergência de se entender e decifrar as novas expressões da questão social, para que se possa pensar estratégias de enfrentamento e até mesmo uma estratégia como solução para as atuais políticas sociais e seu caráter reparatório.

\begin{abstract}
A tese aqui sustentada [...] é a de que inexiste qualquer "nova questão social". O que devemos investigar é, para além da permanência de manifestações "tradicionais" da "questão social", a emergência de novas expressões da "questão social' que é insuprimível sem a supressão da ordem do capital. [...] a cada novo estágio de seu desenvolvimento, ela instaura expressões sócio-humanas diferenciadas e mais complexas, correspondentes à intensificação da exploração que é a sua razão de ser (NETTO, 2001, p. 48).
\end{abstract}

Dessa forma, a esfera da educação se torna um espaço cada vez mais contraditório, uma vez que o que seria um espaço de construção de saberes, criticidade, momento de propor mudanças e participação política, torna-se uma "fábrica de robôs", poder-se-ia assim dizer. Robôs que vão atender às necessidades do capital, gerar mais lucro - para os detentores dos meios de produção - e não têm tempo e muitas vezes saúde para refletirem sobre o que vivenciam no cotidiano.

Logo, deve-se pensar que a universidade tem sido palco dessa produção de trabalhadores para o mercado produtivo. Poucas áreas do conhecimento ou cursos que têm lutado pela oferta de aporte crítico para que haja consciência sobre a realidade social vivida, geralmente estão restritos às áreas de humanas e ciências sociais. Em pesquisa de campo realizada na Universidade Federal do Triângulo Mineiro, Uberaba-MG, acerca dos limites e possibilidades para a permanência de estudantes oriundos da classe menos favorecida, no ensino superior público, percebe-se que, do universo total de sujeitos - 475 alunos atendidos pela Política de Assistência Estudantil entre os anos de 2011, 2012 e primeiro semestre de 2013 — , 235 são das áreas de licenciaturas, humanas e ciências sociais aplicadas, ao passo que apenas 76 são da área de tecnologias e exatas, e 164 da área da saúde. Pode-se dizer que esses alunos são fruto da classe trabalhadora, que se inseriram na universidade, a maioria, 
após a chegada à UFTM do REUNI e do processo de expansão da universidade, principalmente nos cursos noturnos de licenciaturas e Serviço Social.

Grande parcela da população está buscando sua inserção no ensino superior, apropriando-se das "oportunidades" dadas aos trabalhadores, para estudar no seu período de descanso. São estudantes provenientes da classe trabalhadora, que se encontram em situação de vulnerabilidade socioeconômica, necessitando do Programa de Assistência Estudantil.

Mas a grande indagação é se ao se inserirem nos cursos de nível superior, esses discentes conseguem permanecer na universidade ou mesmo se a concessão dos benefícios previstos pelo Programa Nacional de Assistência Estudantil - PNAES tem contribuído para essa permanência. Para tanto, a presente pesquisa mostra os auxílios alimentação, transporte, moradia e permanência, no ano de 2013, que, segundo o Programa Nacional de Assistência Estudantil, decreto 7.234 de 19 de julho de 2010, contribuem para democratizar e ampliar as condições de permanência em instituições federais. Além de objetivar, segundo o artigo $2^{\circ}$, minimizar os efeitos das desigualdades sociais e regionais na permanência e conclusão da educação superior, reduzindo taxas de retenção e evasão, e contribuindo para a promoção da inclusão social.

Para a pesquisa, utilizou-se de uma amostragem probabilística, do tipo estratificada; caracterizando-se como a seleção de uma amostra de cada subgrupo da população considerada, no caso os institutos da Universidade: Instituto de Ciências da Saúde - ICS, Instituto de Ciências Exatas, Naturais e Educação - ICENE, Instituto de Ciências Tecnológicas e Exatas - ICTE, Instituto de Educação, Letras, Artes, Ciências Humanas e Sociais - IELACHS. Para tanto, o critério definido foi de uma amostragem de mais ou menos $10 \%$ (dez por cento) de sujeitos de cada instituto, totalizando 46 sujeitos. No decorrer da pesquisa e aplicação dos questionários, quando indagados se os auxílios são determinantes para sua permanência e conclusão de curso na Universidade, alguns dos sujeitos dos quatro institutos pesquisados apontaram que:

"Sim. O curso multiperiódico limita o tempo, sendo inviável o trabalho remunerado." (CFS)

"Sim, pois é com o auxílio e com a ajuda que meus pais me dão que eu consigo viver na cidade de Uberaba e terminar a faculdade de forma mais digna." (LAD)

"Sim, porque não possuo renda financeira suficiente. O auxílio, mesmo sendo pouco me ajuda." (BFO) 
"Sim. Pois a situação financeira da minha família não seria suficiente para me manter estudando fora de casa." (PMF)

“Os auxílios são determinantes uma vez que a minha renda familiar são seria capaz de suprir nem as necessidades mínimas de um acadêmico que reside fora da sua cidade de origem." (FBF)

"Sim, pois com eles eu posso me manter na cidade, já que no meu caso meus pais não têm condições financeiras para pagar todos os gastos que um estudante morando fora de casa tem." (GAA)

"Sim, tem alunos que tem a vontade de estar em uma universidade e concluir com um rendimento de excelência, porém conseguir isso trabalhando é uma proeza, pois não participa ativamente do curso como um todo (eventos, palestras) e não tem tempo para leituras e outros. Com os auxílios esses problemas em parte são sanados.” (EFS)

"Sim. Primeiramente porque meus pais são trabalhadores autônomos/informais, ou seja, não possuem renda fixa para que se possa comprometer o salário. Segundo porque possuo um irmão que reside em outro município para estudar. Desta forma, meus pais arcam com as despesas de três residências, além das outras necessidades básicas como alimentação, vestuário, lazer.” (NMA)

"Sim, porque me ajuda na alimentação e moradia e outros, dá pra sobreviver com dificuldades, não quero parecer ingrata, quero deixar bem claro, se não fosse o auxílio que recebo não estaria estudando." (RBS)

"Sim, pois mesmo não contemplando todas as minhas necessidades, este auxílio tem sido em muitas situações um "quebra-galho".” (NCF)

"Sim, levando em consideração a distância de minha residência e o valor do transporte urbano, o auxílio alimentação que é um dos auxílios que recebo desde 2010 vem contribuindo e muito para minha permanência, uma vez que eu não trabalho e meus pais recebem pouco mais de um salário mínimo e não temos veículos próprios." (CRS)

"É óbvio. Eu não tenho condições financeiras para me manter na cidade, não tenho dinheiro para comer, para fazer terapia. Como se estuda sem comer e que tipo de qualidade de vida eu tenho?!" (GKN)

Os depoimentos acima apontam que os auxílios financeiros são relevantes para a vida acadêmica, ressaltando especialmente as inúmeras dificuldades econômicas das famílias dos acadêmicos e até mesmo as condições de trabalho, como trabalho autônomo/informal e sem renda fixa. O fato de o curso ser integral, para muitos estudantes, limita a oportunidade de 
trabalhar e, por vezes, o auxílio é determinante para a permanência na universidade. Outro fator que dificulta a permanência no ensino superior público é o fato de o aluno ser proveniente de outra cidade, e a renda da família ser restrita para cobrir todos os gastos. $\mathrm{O}$ transporte também foi mencionado, visto que muitos não possuem veículo próprio e dependem do transporte público e, ao terem que se deslocar todos os dias para estudar, a despesa é alta; assim, o auxílio também contribui para a permanência do estudante no que tange ao deslocamento diário à universidade.

Logo, percebe-se que as expressões da questão social estão também presentes na universidade, já que são muitas as afirmações da importância dos auxílios para a permanência no ensino superior público. Por isso faz-se necessário entender que são inúmeras as dificuldades impostas durante a trajetória acadêmica, e que é preciso que a Assistência Estudantil esteja implementada, com vistas a sanar os efeitos da desigualdade social e promover não só a permanência do estudante, mas também a conclusão do curso.

A universidade é uma expressão da própria sociedade brasileira, abrigando também as contradições nela existentes. A busca pela redução das desigualdades socioeconômicas faz parte do processo de democratização da universidade e da própria sociedade. Esse não se pode efetivar apenas no acesso à educação superior gratuita. Torna-se necessária a criação de mecanismos que viabilizem a permanência e a conclusão de curso dos que nela ingressam, reduzindo os efeitos das desigualdades apresentadas por um conjunto de estudantes provenientes de segmentos sociais cada vez mais pauperizados e que apresentam dificuldades concretas de prosseguirem sua vida acadêmica com sucesso (PLANO NACIONAL DE ASSISTÊNCIA ESTUDANTIL, 2008, p. 04).

Ainda quando questionados sobre o papel dos auxílios para a permanência no ensino superior, outro grupo de sujeitos ressalta que os auxílios contribuem em parte:

"Em partes. Como meus pais moram fora e meu irmão também, fica difícil sustentar 3 casas. Mas na falta dos auxílios daria pra ficar na faculdade, mas com dificuldades." (TCSG)

"Eles não são determinantes mas contribuem bastante, pois, o que recebo de salário no meu trabalho é pouco. Tenho 1 filho de 7 anos e sou mãe solteira." (AJRE)

“Totalmente determinantes eu não diria, mas são de grande peso, são importantes, mas às vezes o valor pago é muito pouco perante a minha necessidade." (CMAS) 
"De certa forma sem o auxílio seria difícil viver em Uberaba, visto que o custo mensal é muito caro, haveria dificuldades, mas não seria determinante para minha permanência e conclusão do curso." (NLF)

De acordo com as respostas, os discentes demonstram que os auxílios contribuem em parte ou não são determinantes para a permanência na universidade; mas foi unânime a afirmação de que eles são importantes e contribuem para o processo de formação, visto que diminuem os percalços e dão qualidade ao curso, uma vez os sujeitos afirmam ter mais tempo para estudar, sem precisar trabalhar. Outros ainda, dizem que o auxílio é apenas um complemento, mas necessário para a permanência em Uberaba e para a conclusão do curso, uma vez que são provenientes de outros municípios.

Para que o estudante possa desenvolver-se em sua plenitude acadêmica, é necessário associar à qualidade do ensino ministrado uma política efetiva de investimento em assistência, a fim de atender às necessidades básicas de moradia, de alimentação, de saúde, de esporte, de cultura, de lazer, de inclusão digital, de transporte, de apoio acadêmico e de outras condições (PLANO NACIONAL DE ASSISTENCIA ESTUDANTIL, 2008 p. 04).

Para tanto, mesmo que alguns sujeitos apontem que os auxílios contribuem em parte para a permanência no ensino superior; é fato que deve ter uma política plena e efetiva de assistência estudantil associada a um ensino de qualidade, como afirma o Plano Nacional de Assistência Estudantil. Os auxílios seriam para alguns apenas um complemento na renda familiar, talvez estudantes não tão pauperizados como os demais que responderam que o auxílio é determinante para a permanência; uma vez que são atendidos alunos de classes com mais e menos vulnerabilidade socioeconômica. Ainda assim, todos os atendidos passam por uma avaliação e são classificados pela ordem de sua necessidade e pela quantidade de recursos que a instituição recebe. Desse modo, alguns ainda necessitam mais que os outros, e o auxílio não se torna um complemento, mas sua fonte de manutenção na universidade, como o primeiro grupo de sujeitos, que responderam que sim, os auxílios são determinantes.

É fundamental articular ações ao processo educativo. Para que a universidade brasileira forme cidadãos qualificados e comprometidos com a sociedade e com a sua transformação, ela deve assumir as questões sociais no seu cotidiano, tornando-se espaço de vivência e de cidadania. Outrossim, o Plano Nacional de Assistência Estudantil, como parte do processo educativo, deverá articular-se ao ensino, à pesquisa e à extensão. Permear essas três dimensões do fazer http://www.uftm.edu.br/revistaeletronica 
acadêmico significa viabilizar o caráter transformador da relação universidade e sociedade. Inseri-la na práxis acadêmica e entendê-la como direito social é romper com a ideologia tutelar do assistencialismo, da doação, do favor e das concessões do Estado (PLANO NACIONAL DE ASSISTÊNCIA ESTUDANTIL, 2008 p. $05)$.

Nesses aspectos apontados, o tripé ensino-pesquisa-extensão da universidade deve estar articulado à dimensão formativa acadêmica, para que a educação seja trabalhada na perspectiva emancipadora. E que os sujeitos entendam os auxílios como direitos, e não como "benesse", "caridade" ou "favor" do Estado; que seja algo que contribua para a permanência do estudante no sentido de formar cidadãos críticos e conscientes, entendendo como realmente um direito de todos os estudantes. Nessa direção, acredita-se que corpo discente, com formação política, poderá atuar diretamente para promover espaços de discussão e construção de novas propostas para ampliação e fortalecimento da política de assistência estudantil.

\begin{abstract}
A nossa principal hipótese é que a ênfase na política de ampliação do acesso não esgota o projeto de democratização da educação superior. Esse processo só se completará se tivermos igual proporção de crescimento na taxa de concluintes, com inclusão crescente das camadas marginalizadas socialmente, sobretudo dos estudantes de baixa renda. É necessário visar com igual ênfase o final do processo: a conclusão, com êxito, dos cursos superiores, incluindo nesses índices as camadas subalternizadas da população (VARGAS; DE PAULA, 2013, p. 464).
\end{abstract}

Conclui-se então que, como Vargas e de Paula assinalam na citação acima, o processo de democratização do ensino superior público inicia-se na igualdade do acesso, que se ampliem as condições para todas as camadas, em especial, as populares, para que possam adentrar o universo da educação superior. Assim, a permanência, por meio da política de assistência estudantil, deve ser reconhecida como peça chave no processo de formação e imprescindível para a conclusão do curso, inserindo as populações de baixa renda em um ensino público de qualidade, oportunizando as mesmas chances de adentrar o mercado de trabalho e se tornarem profissionais qualificados. 


\section{APROXIMAÇÕES CONCLUSIVAS}

Pedro Demo (1997), em seus escritos, diz que "duas competências são essenciais: saber inovar e saber educar a inovação, colocando o conhecimento a serviço dos excluídos". Para tanto, o presente artigo buscou discutir acerca da Política Educacional Brasileira, desde os primórdios, em que a educação era reservada apenas as elites da sociedade; perpassando um período de intensas modificações e a chamada redemocratização, com a chegada da Constituição Federal de 1988 e demais legislações que garantiam o acesso igualitário para o ingresso no ensino superior.

Portanto, a construção desse trabalho buscou trazer marcos importantes, datas e uma certa "linearidade" na história, se existe um sentido figurado para a palavra, seria a melhor expressão para fins didáticos. Mas é válido frisar que a história não possui uma "linha do tempo" gradual, em que se inserem datas fixas, estanques; mas é um movimento, uma unidade de contradições; assim como o ensino superior e seu bojo de historicidade, de dialética, de ambiguidades. Entender o processo histórico é reconhecer como ele impacta em todas as áreas dos saberes, e na educação não é diferente; seus determinantes interferem diretamente no que tange ao acesso da classe menos favorecida no ensino superior público, assim como a criação de condições para a permanência na universidade. A própria Política de Assistência Estudantil é fruto de um governo que se atenta para a população em situação de vulnerabilidade social, diferente de outros anteriores que privilegiavam os interesses da elite. A recente expansão das vagas nas universidades públicas, os programas de ampliação e criação de novos cursos, a abertura de novos concursos públicos, dentre outros avanços também provém de todo o histórico abordado no decorrer do trabalho, da chegada da globalização e de uma maior atenção à classe menos favorecida.

Mas, ainda assim, há entraves que dificultam o acesso igualitário a todos os cidadãos, assim como faz-se necessário garantir a permanência dos estudantes e com um valor de auxílio que supra as necessidades básicas de viver em outra cidade, ou sem depender da família. Portanto, perpassar as fronteiras de um conservadorismo elitizado impregnado no ensino superior, é reconhecer as conquistas e tentar romper com as barreiras que transpõem essa ação conservadora, mostrando que há perspectivas para que a classe em maior vulnerabilidade social possa cada vez mais estar presente na universidade; fazer-se e refazerse na educação. 
A "questão social" aqui estudada, com expressões como desemprego, condições financeiras insuficientes, dificuldades de se manter em uma cidade diferente da sua de origem, vestibular seletista, educação básica que contribui pouco para o ingresso em uma universidade pública, trabalho informal sem renda fixa, salário mínimo que não supre todas as necessidades de alimentação, moradia, vestuário, dentre outras; além das outras limitações do subemprego e sua consequente exploração, é fruto do processo de acumulação capitalista, da contradição capital e trabalho, das ambiguidades presentes no mundo do trabalho. E que seus efeitos estão também na universidade, acarretando em dificuldades em estudar, principalmente para a classe em maior vulnerabilidade social.

Reconhece-se também o frágil engajamento político, a mobilização em favor dos movimentos estudantis, a conscientização e mobilização dos acadêmicos, professores e toda a comunidade com vistas a somar forças para conseguir melhorias na educação. Falta, muitas vezes, um posicionamento crítico em favor da democratização e do acesso ao ensino superior a todos os cidadãos, em defesa também da classe em situação de maior vulnerabilidade social ocupando seu espaço na universidade. A Política Nacional de Assistência Estudantil deve ser entendida então não como algo reparatório, compensatório, mas necessário para dar qualidade aos estudos, para contribuir para a permanência e conclusão dos cursos universitários.

Salienta-se a contribuição dos auxílios para o processo de formação, diminuindo os percalços e dando qualidade ao curso, tendo mais tempo para estudar e alguns não precisando trabalhar, pois têm os auxílios e a ajuda dos pais. Mas outros tendo que sustentar a família e necessitando de mais recursos financeiros, cada qual com suas particularidades. No entanto, cabe refletir que muitas expressões da questão social apontadas nos depoimentos exigiriam mais que uma política de assistência estudantil. Tal realidade social vivenciada pelos discentes da UFTM é um retrato do contexto socioeconômico, político e cultural vivenciado pela classe trabalhadora no Brasil e que exige, para seu enfrentamento, o investimento em uma política para trabalho e renda para uma vida digna.

É preciso entender que a Assistência Estudantil não é somente mais uma política pública, mas sim um direito social de todos, pois a esfera da educação pode ter a tônica do seu desenvolvimento vinculada ao capital, mas não é impossível transformá-la, refazê-la; ao contrário, é uma possibilidade real que se assenta de colocar a educação "a serviço dos excluídos" (DEMO ,1997). A Política de Assistência Estudantil contribui para a permanência dos estudantes no ensino superior público, mas ainda se mostra frágil em aspectos como o valor dos auxílios, que é insuficiente para arcar com todas as despesas de alimentação, 
moradia, e demais necessidades básicas. Muitos beneficiários que não trabalham, devido o curso ser integral, contam com a ajuda de familiares para prover sua subsistência, o que mostra que os auxílios não são totalmente suficientes.

Enfim, para que haja a igualdade de condições é preciso lutar e resistir, é preciso que haja participação política dentro da universidade, que exista uma organização e mobilização de todos os cursos, almejando uma mudança nos processos educacionais, mudanças em busca da inserção da classe trabalhadora também no ensino superior. Deve-se educar para a cidadania, mobilizando em favor de uma cultura prática da democracia e da liberdade; de entender a importância da participação da sociedade nos problemas de âmbito público, de formar cidadãos que sejam autores de sua própria história e livres. Livres no sentido pleno, da superação da lógica subversiva do capital, a fim de entender a Política de Assistência Estudantil como um direito; e não como caridade, favor do Estado, benesse ou assistencialismo. Esse é o principal desafio que se enfrenta na atualidade, o rompimento com o pensamento conservador de que o poder público ajuda, e o entendimento do direito, garantia de efetivação das legislações vigentes.

\section{NOTA}

${ }^{1}$ Para aprofundar os estudos sobre esta questão veja NETTO (2011), ANTUNES (2011), ALVEZ (2011), IAMAMOTO (2011).

\section{REFERÊNCIAS}

ALVEZ, Giovanni. Trabalho e subjetividade: o espírito do toyotismo na era do capitalismo manipulatório. 1 ed. São Paulo: Boitempo, 2011.

ANTUNES, Ricardo. Adeus ao trabalho?: ensaio sobre as metamorfoses e a centralidade no mundo do trabalho. 15. ed. São Paulo: Cortez Editora, 2011.

AZANHA. J. M. P. Política e Planos de Educação no Brasil: alguns pontos para reflexão. São Paulo. Cad. Pesq. n. 85. p. 70-78, 1993.

BENINCÁ, Dirceu. Universidade e suas fronteiras. São Paulo: Outras Expressões, 2011.

BRASIL. Ministério da Educação. Plano Nacional de Assistência Estudantil, 2008. Disponível em: $<$ http://www.jatai.ufg.br/uploads/162/original_Plano_Nacional_de_Assist\%C3\%AAncia_Estudantil.p df?1331733620>. Acesso em: 15 nov 2013.

BRASIL. Universidade Federal do Triângulo Mineiro. Proposta de Pactuação do plano de reestruturação e expansão da Universidade Federal do Triângulo Mineiro - ReUni 2012-2014. 
Disponível em: $<$ http://www.slideshare.net/comissaodiscenteuftm/proposta-de-repactuao-do-plano-dereestruturao-e-expanso $>$. Acesso em: 15 nov 2013.

BRASIL. Universidade Federal do Triângulo Mineiro. Resolução n n. ${ }^{0} 002$, de 14 de abril de 2011. Disponível em:

$<$ http://uftm.edu.br/upload/pesquisa/resolucao e regulamento da ass. estudantil uftm 14.8.pdf $>$. Acesso em: 10 out 2013.

DEMO, Pedro. A nova LDB: Ranços e avanços. 22 ed. Campinas: Papirus, 1997.

IAMAMOTO, Marilda V. Serviço Social em tempo de capital fetiche: capital financeiro, trabalho e questão social. 6. ed. São Paulo: Cortez, 2011.

IAMAMOTO, Marilda Vilela. A questão social no capitalismo. Revista Temporális. Brasília. ano. 2, n. 3, ABEPSS, Grafline, p. 09-32, jan-jul. 2001.

MÉSZAROS, István. A educação para além do capital. [Tradução Isa Tavares]. 2. ed. São Paulo: Boitempo, 2008.

NETTO, José Paulo, Braz, Marcelo. Economia Política: uma introdução crítica. 7. ed. São Paulo: Cortez, 2011.

NETTO, José Paulo. Cinco notas a propósito da "questão social". Revista Temporális, Brasília, ano. 2, n. 3, ABEPSS, Grafline, p. 41-50, jan-jul. 2001.

PASTORINI, Alejandra. A categoria "questão social" em debate. 3. ed. São Paulo: Cortez, 2010.

SAVIANI, D. Sistemas de ensino e planos de educação: O âmbito dos municípios. Educação \& Sociedade. ano XX, n. 69. 1999.

SAVIANI, Demerval. A nova lei da educação: trajetória, limites e perspectivas. 11. ed. Campinas, SP: Autores Associados, 2008.

SILVA, Maria Vieira; MARQUES, Maria Rúbia Alves. (orgs). LDB: balanços e perspectivas para a educação brasileira. Campinas, SP: Alínea, 2008.

TONET, Ivo. Educação contra o capital. 2. ed. São Paulo: Instituto Lukács, 2012.

VARGAS, Hustana Maria; DE PAULA, Maria de Fátima Costa. A Inclusão do estudante-trabalhador e do trabalhador-estudante na educação superior: desafio público a ser enfrentado. Avaliação,

Campinas; Sorocaba, SP. v. 18, n. 2, p.459-485, jul. 2013.

YASBEK, Maria Carmelita. Pobreza e exclusão social: expressões da questão social no Brasil. Revista Temporális, Brasília, ano. 2, n. 3, ABEPSS, Grafline, p. 33-40, jan-jul. 2001.

RECEBIDO EM: 21/03/2014.

APROVADO EM: 25/09/2015. 